\title{
Cerâmicas ácido resistentes: a busca por cimentação resinosa adesiva
}

\section{(Acid resistant ceramics: The search for resinous adhesive cementation)}

\author{
A. S. Malheiros ${ }^{1}$, F. P. Fialho' ${ }^{2}$ R. R. J. Tavarez ${ }^{1}$ \\ ${ }^{I}$ Centro Universitário do Maranhão - UNICEUMA \\ ${ }^{2}$ Associação Brasileira de Odontologia, Av. dos Holandeses 7, Calhau, São Luis, MA
}

\begin{abstract}
Resumo
A eliminação da fase vítrea das cerâmicas odontológicas tornou-as resistentes à fratura, mas também ácido resistentes, o que neste último caso dificulta a cimentação resinosa adesiva. A busca por métodos para condicionar estas cerâmicas tem estimulado inúmeros trabalhos científicos. O tratamento da superfície cerâmica, a descontaminação da superfície e a escolha dos agentes de união e cimentação estão entre os itens considerados importantes. As pesquisas dos últimos cinco anos mostram que ainda não há um protocolo definido de cimentação, contudo os resultados apontam para uma associação de métodos para que a união adesiva seja obtida.

Palavras-chave: cerâmica, cimentos de resina, adesão, superfície modificada.
\end{abstract}

\begin{abstract}
The elimination of the glassy phase of dental ceramics made them resistant to fracture but also acid resistant, which makes it difficult in the latter case the adhesive resin cement. The search for methods to condition these ceramics has stimulated many scientific papers. The ceramic surface treatment, decontamination of the surface and the choice of coupling agents and cement are among the items considered important. Researches in the last five years show that there is still no established protocol for cement, but the results point to a combination of methods for the adhesive bond is obtained.
\end{abstract}

Keywords: ceramic, resin cement, adhesion, surface modification.

\section{INTRODUÇÃO}

As cerâmicas são, sem dúvida, um dos materiais odontológicos de grande expressão na odontologia moderna. São biocompatíveis, apresentam alta resistência à compressão, estabilidade química, e grande potencial estético, pois permitem reconstruir artificialmente as particularidades das estruturas dentais, características importantes na reabilitação estética e funcional. São compostas de elementos metálicos ( $\mathrm{Al}, \mathrm{Ca}, \mathrm{Li}, \mathrm{Mg}, \mathrm{K} . \mathrm{Na}$, $\mathrm{Zr}$, Ti) e não metálicos $(\mathrm{O}, \mathrm{Si}, \mathrm{B}, \mathrm{F})$. A combinação destes pelos fabricantes resulta em duas fases distintas. Fase vítrea ou amorfa e fase cristalina ou mineral [1]. A fase vítrea confere propriedades de transmissão de luz, o que possibilita a reprodução de características óticas de translucidez em vários níveis. A fase cristalina é responsável pela resistência, pois funciona como uma barreira impedindo a propagação de trincas. O percentual cristalino bem como o tipo de cristal presente na microestrutura, influenciará diretamente na translucidez e opacidade da cerâmica, sendo a fluorescência e opalescência garantidas pela inserção de óxidos metálicos na composição da cerâmica. Então, para obter boas características estéticas, o fabricante mantém um percentual significativo de fase amorfa, e um menor percentual de fase mineral. Esta diminuição, no entanto, leva a uma menor resistência intrínseca do material, tornando-o mais propenso a fratura [2]. A baixa tenacidade a fratura é reconhecidamente uma das maiores desvantagens do material cerâmico. A tentativa de minimizar ou mesmo solucionar tal problema baseia-se atualmente em dois pontos chaves: alteração estrutural da cerâmica e cimentação resinosa.

Para melhor entendimento deste contexto, quatro grupos cerâmicos serão considerados: porcelanas, vitro-cerâmicas, compositos e cerâmicas policristalinas [3] (Tabela I).

As três primeiras conferem resultado estético e permitem cimentação resinosa adesiva, pois as partículas de reforço inseridas na composição ou mesmo criada a partir da forma de processamento da cerâmica, na sua maioria, não comprometem o condicionamento ácido. Diferente do último grupo que basicamente é composto por cristais, particularidade que aumenta em muito a resistência, em contra partida, acentua a opacidade e impede o condicionamento ácido, sendo por isto ditas ácido-resistentes [4].

Idealmente as restaurações cerâmicas devem ser cimentadas ao pilar por meio de cimento resinoso, que apresenta excelente selamento interfacial, é praticamente insolúvel, e permite a transferência da tensão gerada sobre a cerâmica à estrutura de suporte (esmalte, dentina, núcleos), o que confere uma maior resistência extrínseca da cerâmica. A cimentação resinosa adesiva também melhora o prognóstico em casos de pilares curtos ou muito convergentes ou mesmo preparos que são, naturalmente, expulsivos (facetas), pois garante a retenção pela adesão. A adesão cerâmica-cimentopilar de suporte, até o então aparecimento das policristalinas, estava bem definida. Basicamente condiciona-se com ácido tanto a parte interna da restauração cerâmica (fluorídrico) 
Tabela I - Grupos cerâmicos, caracteristícos, representantes, indicações e cimentação.

[Table I - Ceramic groups, characteristics, representatives, indication and cementation.]

\begin{tabular}{|c|c|c|c|c|}
\hline $\begin{array}{c}\text { Grupos } \\
\text { Cerâmicos }\end{array}$ & Características & Representantes & Indicações & Cimentação \\
\hline Porcelana & $\begin{array}{l}\text { A maioria é produzida } \\
\text { a partir do feldspato. } \\
\text { Apresentam matriz vítrea } \\
\text { onde frequentemente } \\
\text { estão dispersas partículas } \\
\text { cristalinas, como: alumina, } \\
\text { fluorapatita ou leucita, sendo } \\
\text { esta última a mais freqüente. }\end{array}$ & Feldspática- Noritak & $\begin{array}{c}\text { Cobertura de infra- } \\
\text { estrutura metálica } \\
\text { (metalocerâmicas) } \\
\text { Inlays, onlays e facetas } \\
\text { Recobrimento de infra- } \\
\text { estrutura cerâmica (metal } \\
\text { free) }\end{array}$ & $\begin{array}{l}\text { Ácido sensível } \\
\text { Cimento resinoso }\end{array}$ \\
\hline $\begin{array}{l}\text { Vitro- } \\
\text { cerâmicas }\end{array}$ & $\begin{array}{l}\text { Microestrutura similar às } \\
\text { porcelanas com leucita, } \\
\text { sendo diferente apenas pela } \\
\text { maior homogeneidade. } \\
\text { Outros cristais utilizados no } \\
\text { reforço são : dissilicato de } \\
\text { lítio. As partículas cristalinas } \\
\text { são adicionadas por } \\
\text { tratamento térmico, chamado } \\
\text { ceramização. }\end{array}$ & $\begin{array}{l}\text { Empress Esthetic-Ivoclar } \\
\text { (cristais leucita) }\end{array}$ & $\begin{array}{c}\text { Inlays, onlays, facetas, } \\
\text { coroa anteriores e } \\
\text { posteriores, e recobrimento } \\
\text { de infraestrutura cerâmica } \\
\text { Inlay, onlay, } \\
\text { facetas,Infraestrutura de } \\
\text { coroas totais e prótese fixa } \\
\text { de até } 3 \text { elementos anterior } \\
\text { ou posterior até premolares }\end{array}$ & $\begin{array}{l}\text { Ácido sensível } \\
\text { Cimento resinoso }\end{array}$ \\
\hline Compósitos & $\begin{array}{c}\text { Constitui-se de uma fase } \\
\text { cristalina em cujos espaços } \\
\text { intersticiais encontra-se } \\
\text { um vidro amorfo, que foi } \\
\text { infiltrado. }\end{array}$ & $\begin{array}{c}\text { In Ceram (Vita) em } 3 \text { versões: } \\
\text { Spinell } \\
\text { Alumina }\end{array}$ & $\begin{array}{c}\text { Coroa anterior } \\
\text { Coroas totais anteriores e } \\
\text { posteriores e prótese fixa, } \\
\text { anterior, de } 3 \text { elementos } \\
\text { Prótese fixa anterior de } 3 \\
\text { elementos, coroa posterior, } \\
\text { ponte fixa posterior } 3 \\
\text { elementos até primeiro } \\
\text { molar. }\end{array}$ & $\begin{array}{c}\text { Ácido resistente } \\
\text { Cimento resinoso } \\
\text { Ácido resistente } \\
\text { Cimento resinoso } \\
\text { Ionômero ou } \\
\text { fosfato } \\
\text { Ácido resistente } \\
\text { Cimento resinoso } \\
\text { Ionômero ou } \\
\text { fosfato }\end{array}$ \\
\hline
\end{tabular}

\begin{tabular}{|c|c|c|c|c|}
\hline \multirow{4}{*}{ Policristalina } & & Alumina Pura & \multirow{4}{*}{$\begin{array}{l}\text { Infraestrutura de coroas } \\
\text { totais e próteses fixas de } \\
\text { até } 3 \text { elementos em dentes } \\
\text { anteriores e posteriores }\end{array}$} & \multirow{4}{*}{$\begin{array}{l}\text { Ácido resistente } \\
\text { Cimento resinoso } \\
\text { Ionômero ou } \\
\text { fosfato }\end{array}$} \\
\hline & $\begin{array}{l}\text { Estrutura unicamente } \\
\text { cristalina por isso }\end{array}$ & Procera AllZirkon - Nobel & & \\
\hline & $\begin{array}{l}\text { apresentam as melhores } \\
\text { propriedades mecânicas e }\end{array}$ & Cercon - Dentsply & & \\
\hline & grande opacidade. & $\begin{array}{l}\text { Zircônia tetragonal } \\
\text { estabilizada por ítrio- VITA }\end{array}$ & & \\
\hline
\end{tabular}

quanto o pilar, preferencialmente estrutura dentária, (ácido fosfórico) criando microretenções que serão preenchidas por um adesivo. Este por sua vez estabelece uma ligação química com o cimento resinoso possibilitando uma união resinosa adesiva.

A compactação existente entre os cristais das policristalinas não permite o condicionamento ácido o que inviabiliza a obtenção de uma cimentação resinosa adesiva $[5,6]$. O desafio, portanto, é encontrar uma forma de criar irregularidades na superfície desta cerâmica.

Esta revisão objetiva abordar os recursos utilizados, atualmente, na busca por uma união adesiva entre cerâmicas policristalinas e o cimento resinoso, bem como discutir a sua efetividade. A cimentação adesiva envolve basicamente 
uma interrelação entre o tratamento de superfície, limpeza dos aderentes e obviamente a seleção adequada do agente de cimentação.

\section{TRATAMENTO SUPERFÍCIE CERÂMICA}

O tratamento da superfície cerâmica promove alterações na topografia, criando microporosidades e rugosidades, o que por sua vez permite o aumento da área superficial disponível para adesão, favorece o embricamento mecânico para retenção do agente de união (silano) e ainda possibilita um melhor molhamento, pelo aumento da energia de superfície [7]. Dentre os métodos existentes para este fim tem-se jateamento, laser, e soluções ácidas. O jateamento é um recurso que consiste em levar de encontro à superfície interna da restauração, substâncias capazes de criar rugosidades. O óxido de alumínio é a substância utilizada há mais tempo para este fim. Recentemente incorporou-se a ele um ácido sílico. Isto permitiu que fosse depositada uma camada de sílica na área jateada e por isso este processo é chamado silicatização [8]. Para diversos pesquisadores a grande vantagem desta última é sua capacidade em penetrar na superfície cerâmica $(15 \mu \mathrm{m})$ além de aumentar em 76\% a concentração de silício, possibilitando união mecânica e química, pois o agente de união que posteriormente é pincelado na superfície cerâmica é a base de sílica [8-10]. Nesse contexto, é importante considerar o tamanho das partículas e o tipo de cerâmica, pois existem resultados positivos com determinadas cerâmicas e pouco efetivos com outras. Acredita-se que o jateamento com partículas maiores são mais efetivas. A dúvida é se isso pode causar microtrincas que venham a danificar estruturalmente a cerâmica. É sugerido trinta micrômetros como um tamanho adequado [11]. A pressão usada no jateamento também é importante, pois constatou-se um aumento da força adesiva quando se aumentou a pressão de 0,05 para 0,25 [12]. O laser é considerado como outra opção de tratar a superfície cerâmica. No entanto ainda não está bem explicado como age. Acredita-se que ele não é efetivo na criação de rugosidade, contudo é capaz de aumentar a força adesiva. Isto devido à criação de microtrincas na superfície e automaticamente microretenções [13]. Enfatizase ainda que a força adesiva não depende da rugosidade $\mathrm{e}$ sim de micro-retenção e acrescenta-se que o jateamento cria irregularidades na superfície sem microretenção e por isso, nos trabalhos que simulam tempo (ciclagem térmica), geralmente ocorre diminuição da força adesiva nos grupos tratados com jateamento [13]. Ao avaliar a efetividade de três tipos de laser: carbono, Nd:YAG (Neodymium-Yttrium Aluminum Garnet) e Er:YAG (Erbium-Yttrium Aluminum Garnet) na cerâmica de zircônia estabilizada por ítrio observaram que apenas o Nd:YAG não foi efetivo [5]. O uso de uma solução ácida aquecida também vem sendo sugerido por alguns pesquisadores $[14,15]$. A explicação é que esta causa um processo controlado de corrosão que dissolve grãos da estrutura da cerâmica (zircônia) ampliando o limite dos grãos por remoção preferencial dos menos organizados e aumentando a energia de superfície dos átomos periféricos. Outra forma citada seria a cobertura da superfície com um vidro que contém agente condicionante (composto de sílica, alumina, óxido de sódio e potássio e óxido de titânio) e que é aquecido acima da temperatura de transição do vidro. Após o resfriamento, o vidro é dissolvido em um banho ácido, criando poros na superfície e alcançando promissores resultados na força adesiva ao cimento resinoso [16]. A criação de uma camada de óxido de fluoreto na superfície da zircônia como forma de aumentar a reatividadee com isso facilitar a adesão, é uma técnica recente que apresentou bons resultados. Segundo os autores que a defendem, isto permitiria o aumento da molhabilidade e adesão química para vários materiais dentários $[17,18]$.

\section{DESCONTAMINAÇÃO DA RESTAURAÇÃO}

A manipulação da restauração no processo de adaptação ao pilar propicia contaminação da mesma com saliva, substâncias orgânicas, e agentes evidenciadores. Uma negligência nesta etapa pode levar a uma diminuição da energia de superfície da cerâmica, bem como comprometimento da adesão [14, 19-21].

Dentre os métodos citados na literatura tem-se: banho ultrassônico, ácido fosfórico 37\%, isopropanol 96\% e 99\%, acetona, jato de ar livre de óleo, jateamento. O uso de ultrassom tem gerado discordância, pois alguns acreditam que superfícies que foram silicatizadas teriam a adesão comprometida pela remoção das partículas de sílica [6].

O ácido fosfórico mostrou ser efetivo na diminuição da contaminação pela saliva, mas não do evidenciador. Além disso, diminui a energia de superfície o que colabora mais ainda no decréscimo da força adesiva [19]. O uso de álcool ou mesmo acetona não têm dado bons resultados, pois não conseguem eliminar todos os contaminantes que podem estar presentes na superfície cerâmica. Em consequência disso relatos de diminuição da força adesiva ou mesmo descimentação espontânea são citados na literatura [19, 20]. $\mathrm{O}$ jateamento da superfície é apontado por vários trabalhos como o método mais efetivo na limpeza da cerâmica. O jateamento com óxido de alumínio $(50 \mu \mathrm{m})$, numa pressão de 2.5 bar por $15 \mathrm{~s}$, foi capaz de reduzir a contaminação por saliva e eliminar por completo resíduos de silicone provindos de soluções evidenciadoras [19].

\section{SELEÇÃO DO CIMENTO}

As cerâmicas ácido-resistentes pela dificuldade de serem condicionadas podem ser cimentadas com cimentos de fosfato zinco ou de ionômero de vidro modificado. Contudo o resinoso é geralmente o escolhido, pois apresenta propriedades importantes como insolubilidade, resistência a abrasão, conferindo desta forma melhor retenção e adaptação marginal, além de diminuir as chances de cárie secundária [7, 22]. Basicamente têm-se hoje três grupos de cimentos resinosos: os convencionais, os autocondicionantes e, mais recentemente, os adesivos. Os dois primeiros necessitam 
obrigatoriamente de agentes de união nas superfícies dos aderentes para garantir uma união adesiva ao cimento $[8,9$, 23]. Já o adesivo apresenta afinidade química tanto com a cerâmica quanto com a estrutura dentária, pois apresenta em sua composição monômeros adesivos como o 4-META e o 10 MDP que se unem muito bem aos óxidos da cerâmica e ao cálcio do dente (MDP) ou ao grupo hidroxila da dentina (META). Por esta característica têm sido frequentemente testados nas cerâmicas ácido resistentes [22,24]. O cimento contendo 10-MDP (Clearfil Esthetic Cement) mostrou ser mais efetivo na adesão à cerâmica de zircônia se comparado ao auto-adesivo ou ao cimento resinoso convencional e, além disso, não requer nenhum pré-tratamento na superfície cerâmica antes da cimentação. A dúvida é quanto a durabilidade dessa adesão química cimento-cerâmica [7].

Três cimentos resinosos, que contêm diferentes monômeros fosfatados (Panavia, Multilink Automix e Rely $\mathrm{X}$ UniCem) foram avaliados quanto à força adesiva na união à zircônia. $\mathrm{O}$ cimento Panavia foi o que melhor resistiu, seguido por Rely X e Multilink, respectivamente, sendo que no primeiro e no último predominaram as falhas coesivas no cimento e no outro as falhas foram interfaciais (cimentozircônia). Esta menor efetividade na união do Rely $\mathrm{X}$ à zircônia acredita-se ser resultado da baixa molhabilidade, devido ao tamanho grande das partículas de carga, e da maior viscosidade do cimento, o que dificulta o escoamento do mesmo nas irregularidades superficiais [23].

$\mathrm{O}$ uso de primers ou mesmo silanos e adesivos contendo MDP também são considerados importantes. Tudo indica que o uso desses aumenta a força adesiva, mesmo nas pesquisas que aplicam termociclagem [21,25].

Cinco cimentos resinosos, todos contendo sílica na composição, e 6 primers com silano na composição foram testados. Os resultados mostraram que os primers foram efetivos no aumento da adesão e que os que apresentavam monômero de ácido fosfórico (MDP) ou monômero de Ester fosfato apresentaram melhores resultados. Chama-se atenção ainda ao fato de que mesmo sem utilizar o primer o cimento com MDP na composição foi efetivo na adesão à cerâmica de zircônia [22].

Uma constatação que tem se tornado frequente em trabalhos mais recentes, é uma maior efetividade da adesão quando o silano e o adesivo contendo monômero MDP são misturados. Acredita-se que isto ocorra devido ao aumento da molhabilidade e da presença de uma união química [21, 25].

\section{DISCUSSÃO}

As pesquisas que objetivam a efetividade da cimentação adesiva para cerâmicas ácido-resistentes ressaltam cada vez mais a necessidade de utilizar uma associação de métodos que em conjunto aumentem a força adesiva, permitindo sua durabilidade. Nesse contexto o tratamento de superfície, a forma de descontaminar a cerâmica, e o cimento utilizado, são os pontos-chaves e por isso têm sido associados de diferentes formas buscando maior efetividade. Diversos autores acreditam que o tratamento na superfície, para criar rugosidades ou microretenções, é essencial para uma cimentação adesiva. Os jateamentos com óxido de alumínio e silicatizações são os métodos mais frequentes e também dividem opiniões de qual é o mais efetivo na criação de rugosidades e principalmente microretenções $[6,7,10$, 11]. Algo que freqüentemente se discute é o tamanho das partículas usadas. As maiores são mais efetivas, por outro lado podem causar danos estruturais. Ao que tudo indica, é preferível trabalhar com partículas menores e, se necessário, aumentar a pressão como forma de obter maior efetividade, principalmente se a cerâmica for zircônia estabilizada com ítria, pois grandes impactos na superfície desta cerâmica induzem a sua mudança estrutural, o que pode comprometer sua resistência [26]. O uso de lasers ou substâncias aquecidas parece ser efetivo; contudo ainda há dúvidas de como agem e por isso são necessárias mais pesquisas para que um protocolo seja melhor definido. Nem todo laser é efetivo, pois o de Nd:YAG não consegue alterar de forma satisfatória a superfície cerâmica, já o de carbono e o Er:YAG são boas opções, mas não devem ser utilizados após jateamento; se isto for feito ao invés de aumentar a força adesiva, ocorrerá uma diminuição pela eliminação das rugosidades obtidas, previamente, com o jateamento $[6,13]$. Independentemente do método utilizado para tratar a superfície cerâmica e da sua efetividade, algo é inquestionável: que a contaminação por saliva, ou outros agentes, diminui as chances de uma efetiva cimentação adesiva. Dentre os vários métodos de descontaminação, o jateamento com óxido de alumínio tem se mostrado como um dos mais efetivos. A limpeza em ultrasom é outra opção viável, contudo deve-se evitar soluções à base de álcool ou acetona, pois estas diminuem a adesão [20]. Uma pesquisa constatou que o método de limpeza (jato de ar livre de óleo, ultra-som onde se utilizou isopropanol a 99\%) não influenciou diretamente no aumento da força adesiva. E atribuem-se os resultados positivos ao uso de um primer universal que contém silano e monômero fosfatado na composição. Esta conclusão enfatiza uma tendência das pesquisas mais recentes, nas quais se credita à escolha do cimento, adesivos e primers o maior diferencial na obtenção da força adesiva cimento-restauração [20, 21].

Dentre as opções de agentes de cimentação e adesivos, os fosfatados (MDP e META) têm demonstrado maior efetividade do que os convencionais e auto-condicionantes, devido à afinidade química que apresentam [22, 23]. Teoricamente, por esta característica, eles dispensariam a necessidade de condicionar a superfície dos aderentes. Contudo algumas pesquisas mostram que quando é feita simulação de tempo, há uma diminuição na adesão. A explicação seria o fato da superfície nativa da zircônia apresentar apenas 5,4\% de cobertura pelo grupo hidroxila (-OH), que é o elo de união com os monômeros fosfatados, o que mostra poucos grupos para uma efetiva adesão química. Considerando esta informação, muitos recomendam que antes deva ser feito um tratamento na superfície para criar rugosidade e ou micro-retenção, permitindo além da união química uma ligação mecânica $[9,22,24]$. Outra opção é o tratamento da superfície com gás fluorado que, em pesquisas 
recentes, mostrou melhora na força adesiva com ou sem o uso de primers organossilano [18].

\section{CONCLUSÃO}

A revisão da literatura dos últimos seis anos deixa claro que não existe um protocolo definido para obtenção de uma cimentação resinosa e adesiva. O desafio de condicionar cerâmicas ácido-resistentes permanece. Ao que tudo indica os resultados são mais favoráveis e promissores à zircônia do que à alumina. Isto nos leva a pensar também que devido a diferenças estruturais é mais provável que o protocolo de cimentação varie em decorrência do tipo de cerâmica usada. Outra tendência é que seja utilizada uma associação de métodos dentro do protocolo de cimentação para alcançar o objetivo da adesão.

\section{REFERÊNCIAS}

[1] J. R. Kelly, Dental ceramics. What is this stuff anyway?, J. Am. Dental Ass. 139 (2008) 4s-7s.

[2] F. Spear, J. Holloway, Which all-ceramic system is optimal for anterior esthetics?, J. Am. Dental Ass. 139 (2008) 19s-24s.

[3] A. S. Fonseca, Odontologia estética a arte da perfeição, Ed. Artes Médicas, S. Paulo, SP (2008).

[4] E. A. Gomes, W. G. Assunção, E. P. Rocha, P. H. Santos, Cerâmicas odontológicas: o estado atual, Cerâmica 54 (2008) 319-325.

[5] A. Della Bona, "Adesão as Cerâmicas-Evidências Científicas para o uso Clínico", Ed. Artes Médicas, S. Paulo, SP (2009).

[6] M. S. Akyil, I. H. Uzun, F. Bayindir, Bond Strength of resin cement to yttrium-stabilized tetragonal zirconia ceramic treated with air abrasion, silica coating, and laser irradiation, Photomed. Laser Surg. 28, 6 (2010) 801-808.

[7] R. C. Oyague RC, Monticelli F, Toledano M, Osorio $\mathrm{E}$, Ferrari M, Osorio R. Influence of surface treatments and resin cement selection on bonding to densely-sintered zirconium-oxide ceramic, Dent. Mater. J. 25, 2 (2009) 172179.

[8] R. P. Palacios, G. H. Johnson, K. M. Phillips, A. J. Raigrodski, Retention of zirconium oxide ceramic crowns with three types of cement, J. Prosthet. Dent. 96, 2 (2006) 104-14.

[9] S. S. Atsu, M. A. Kilicarslan, H. C. Kucukesmen, P. S. $\mathrm{Aka}$, Effect of zirconium-oxide ceramic surface treatments on the bond strength resin, J. Prosthet. Dent. 95, (2006) 230236.

[10] A. Della Bona, M. Borba, P. Benetti, D. Cecchetti., Efeito de tratamentos de superficie sobre a resistência de união entre cerâmica reforçada por zircônia e resina composta, Braz. Oral Res. 21 (2007) 10-15.

[11] S. S. Scherrer, M. C. Lorente, E. Vittecoq, F. Mestral, J. A. Griggs, A. H. W. Wiskott, Fatigue behavior in water of
Y-TZP zircônia ceramics after abrasion with $30 \mu \mathrm{m}$ silica alumina particles, Dent. Mater. 27, 2 (2011) 28-42.

[12] B. Yang, A. Barloi, M. Kern., Influence of air-abrasion on zirconia ceramic bonding using an adhesive composite resin, Dent. Mater. 26, 1 (2010) 44-50.

[13] E. Bahadir, B. Yuzugullu, A. R. Yazici, S. Canay, Surface roughness and Bond strengths of glass-infiltrated aluminaceramics prepared using various surface treatments, J. Dent. 37 (2009) 848-856.

[14] A. Casucci, E. Osorio, R. Osorio, F. Monticelli, M. Toledano, C. Mazzitelli, M. Ferrari, Influence of different surface treatments on surface zirconia frameworks, J. Dent. 37, 11 (2009) 891-897.

[15] E. Osorio, M. Toledano, B. L. Silveira, R. Osorio, Effect of different surface treatments on In-ceram alumina roughness, An AFM study, J. Dent. 38, 2 (2010) 118-22.

[16] A. P. Manso, N. R. F. A. Silva, E. A. Bonfante, R. A. Dias, Cements and adhesives for all-ceramic restorations, Dent. Clin. North Am. 55, 2 (2011) 311-332

[17] J. R. Piascik, S. D. Wolter, B. R. Stoner, Development of a novel surface modification for improved bonding to zirconia, Dent. Mater. 27, 5 (2011) 99-105.

[18] J. R. Piascik, E. J. Swift, K. Braswell, B. R. Stoner, Surface Fluoration of zirconia: Adhesive bond strength comparison to commercial primers, Dent. Mater. 28 (2012) 604-608.

[19] B. Yang, S. Wolfart, M. Scharnberg, K. Ludwig, R. Adelung, M. Kern, Influence of contamination on zirconia ceramic bonding, J. Dent. Res. 86, 8 (2007) 749-753.

[20] A. C. Quaas, B. Yang, M. Kern, F. Panavia, 2.0 bonding to contaminated zirconia ceramic after different cleaning procedures, Dent. Mater. 23, 4 (2007) 506-512.

[21] A. Attia, F. Lehmann, M. Kern, Influence of surface conditioning and cleaning methods on resin bonding to zirconia ceramic, Dent. Mater. 27, 3 (2011) 207-13.

[22] S. Kitayama, T. Nikaido, R. Takahashi, L. Zhu, M. Ikeda, R. M. Foxton, R. Asdr, J. Tagami, Effect of primer treatment on bonding of resin cements to zirconia ceramic, Dent. Mater. 26, 5 (2010) 426-432.

[23] H. Mirmohammadi, M. N. M. Aboushelib, Z. Salameh, A. J. Feilzer, C. J. Kleverlaan, Innovations in bonding to zirconia based ceramics: part III. Phosphate monomer resin cements, Dent. Mater. 26, 8 (2010) 786-792.

[24] J. Y. Thompson, B. R. Stoner, J. R. Piascik, R. Smith, Adhesion/cementation to zirconia and other non-silicate ceramics: Where are we now?, Dent. Mater. 27, 1 (2011) 71-82.

[25] R. Tanaka, A. Fujishima, Y. Shibata, A. Manabe, T. Miyazaki, Cooperation of Phosphate monomer and silica modification on zirconia, J. Dent. Res. 87, 7 (2008) 666-670. [26] A. R. Curtis, A. J. Wright, G. J. P. Fleming, The influence of surface modification techniques on the performance of a Y-TZP dental ceramic, J. Dent. 34, 3 (2006) 195-206.

(Rec. 20/05/2011, Rev. 08/11/2011, 22/05/2012, Ac. 14/08/2012) 